https://doi.org/10.48009/2_iis_2007_127-133

\title{
A COMMUNICATION MODEL FOR VIRTUAL COLLABORATION
}

\author{
Gary Baker, Sam Houston State University, garybaker@shsu.edu \\ David Taylor, Sam Houston State University, davidtaylor@shsu.edu
}

\begin{abstract}
Globalization and the changing structures of organizations have created work groups that are distributed across space (different sites) and time. Collaboration among and between organizations is needed to support outsourcing strategies. As organizations focus on long term outsourcing and off-shoring relationships, effective communication is often seen as an important factor contributing to the success of individuals, project teams, and organizational growth. The adoption of global business models are enabled by the deployment of advanced technology to extend the usefulness of IT in support of distributed work environments. This research focuses on communication medium, decision quality, and group cohesiveness as important factors in determining the effectiveness of virtual teams.
\end{abstract}

Keywords: Collaboration Technologies, Virtual Teams, Strategic Decisions.

\section{INTRODUCTION}

The integration of systems within and between organizations has led to the development of new organizational forms which are more flexible and responsive, [11, 20, 21]. Virtual teams consist of geographically dispersed members, who need to collaborate to accomplish ongoing or project-based activities. Zigurs and Qureshi [26] describe how collaborative systems and communications technologies have enabled the formation of virtual organizations and virtual teams consisting of individuals who are geographically and organizationally disbursed. Meyerson et al. [18] described the importance of early communication and interaction in the development of "swift" trust among virtual team members.

Collaborative technologies include a wide range of asynchronous and synchronous tools. Asynchronous tools such as email, calendaring systems, and project management systems support coordination activities. Shared work spaces such as group discussion boards and information repositories enable the sharing of knowledge. Finally technologies such as chat rooms, whiteboards, audioconferencing and videoconferencing support virtual synchronous discussions. As the growth of virtual teams continues, the ability to work collaboratively via computer networks is becoming an important core competency of organizations [1, 2]. This paper builds on literature from problem solving, group communication and electronic media. The model is developed to provide a basis for studying the impact of different features of technologies on the collaboration of virtual teams.

\section{THEORETICAL BACKGROUND}

Much of the current research on collaborative technologies stems from the profound effect that technology has on individuals working in groups [23, 24]. Short, Williams and Christie [22] developed a theory of group interaction based on social presence, defined as the degree to which a medium supports the psychological presence of users during an interaction. Social presence includes factors such as sociability, warmth, personalness and sensitivity. According to the social presence theory, the more channels or codes available within a communication medium, the more attention paid by the user to the presence of other social participants. In addition to communication media, the type of task being undertaken is an important factor in studying collaborative teams. While email and telephone conversations provide tools to support the collection and dissemination of needed information, they fail to provide the non-verbal cues that contribute to effective task oriented communication [1].

Empirical studies comparing computer mediated and face-to-face groups have examined the varying effects of technology on group processes, performance, and user satisfaction. Research on virtual teams using computer-mediated communication has provided evidence of the impact which technology can have on different aspects of group decision making [5, 8, 10]. Dennis et al. [4] focus on the ability of technologies to support the feedback and concurrency capabilities of collaborative communication. Feedback refers to the ability of a medium to provide rapid bi-directional communication and the ease with which the receiver can interrupt the sender. Concurrency refers to the number of simultaneous conversations that can exist effectively in the medium. Dennis' media synchronicity theory (MST) is described as: "the extent to which the environment encourages 
individuals to work on the same activity, with the same information, at the same time" (p. 48). MST proposes that communication effectiveness results from matching the communication capabilities of concurrence and feedback to the communication processes of conveyance (the exchange of information) and convergence (the development of a shared meaning about information), see Table 1.

Table 1: Feedback and Concurrency Saliency of Communication Media

\begin{tabular}{|c|l|c|c|}
\hline \multirow{2}{*}{} & \multicolumn{3}{|c|}{ Feedback } \\
\cline { 2 - 4 } & & $\begin{array}{c}\text { No Video } \\
\text { (Low-Medium) }\end{array}$ & $\begin{array}{c}\text { Video } \\
\text { (Medium-High) }\end{array}$ \\
\cline { 2 - 4 } & $\begin{array}{c}\text { Text } \\
\text { (High) }\end{array}$ & Text-only & Text-Video \\
\cline { 2 - 4 } & $\begin{array}{c}\text { Audio } \\
\text { (Low) }\end{array}$ & Audio-only & Audio-Video \\
\hline
\end{tabular}

Successful performance of a task requires not only that team members convey their ideas and understanding of the dilemma, but also that members develop a common shared understanding of the issues and the team's strategy. Conveyance is defined as the imparting or communicating by statement whose "goal is to enable the most rapid exchange of information among participants as possible, and to enable them to effectively process this information and arrive at their individual interpretations of its meaning", [4, p.52]. While the purpose of many virtual teams is to develop a recommendation for a specific problem or issue, much of the time spent by the individuals is in the exchange of information. This involves not just relating facts and figures but also providing some background and context to understand the many issues involved. Weick and Meader's [25] sensemaking activities of action, triangulation, and contextualization depend on the exchange of information supported by the conveyance process. As team members share and exchange information, the conveyance process is enhanced by the capability of multiple concurrent communications while feedback plays a minor role.

\section{CONCEPTUAL MODEL}

As problem solving and decision making move from face-to-face to virtual environments it is important to re-examine factors that have been shown as important for task performance in face-to-face teams. Mills [19] and Fisher [7] describe communication and decision making as representing the two most common activities performed by groups. In a traditional medium such as telephone, only one conversation can effectively use the medium at a time. Although audio-only and text-only communication provides fewer cues than other media, these cues are generally more salient since they are not competing with other cues available in face-to-face (or video conferencing) communication [15]. In many cases, the greater concurrency of textbased media allows the generation of more divergent ideas. These multiple conversations however mean that it can be more difficult to focus on one topic or issue.

This research study will focus on four different communication media: text-only, audio-only, textvideo, and audio-video. Using media synchronicity and results from other studies as a guideline, it is anticipated that text-based communication with high concurrency allows group members to convey more ideas and develop better strategies even though the feedback is less immediate than audio-based

Figure 1: Research Model

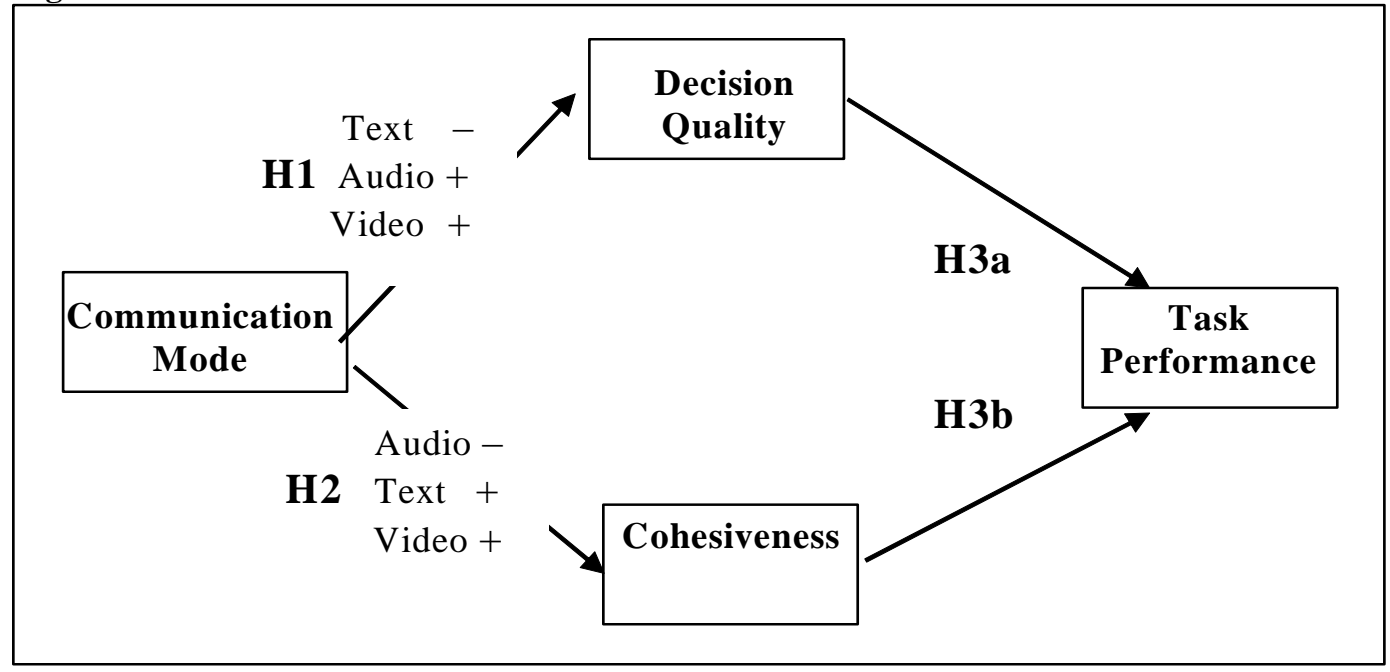


communication. However, as group members attempt to develop a common strategy, the higher feedback provided by the addition of video to both text-based and audio-based communication should improve the convergence process leading to improved strategy. Thus the first hypothesis is:

H1a: Audio-only communication will have a negative impact on the quality of the strategy decision when compared to text-only.

H1b: The addition of video will have a positive impact on the quality of the strategy decision when compared to no-video communication.

While the purpose of many virtual teams is to develop a recommendation for a specific problem or issue, much of the time spent by the individuals is in the exchange of information. In his seminal work of groups Festinger [6] defines group cohesiveness as "the result of all the forces acting upon the members to remain in the group". Interpersonal communication can be viewed as the organizing element for individuals in a group and has been shown to be one of the most important means for gaining the commitment to the task and to the group itself [13]. In describing the positive effects of cohesiveness on team members Cartwright and Zander [3] state "The improved interpersonal relations involved in an increase in cohesiveness lead to more acceptance, trust, and confidence among members and ... each member consequently develops a sense of security and personal worth" (p. 104). The convergence process of developing a shared meaning among group members can be linked to the affiliation process of comparing views and negotiating shared understanding. For the convergence process, media that focus the communication onto a single issue help in developing a common shared understanding. Thus environments that provide a low communication concurrency and a high immediacy of feedback are preferred for convergence processes. Thus the second hypothesis is:

H2a: Audio-only will result in higher group cohesiveness when compared to text-only computer mediated communication.

H2b: The addition of video will have a positive impact on cohesiveness when compared to novideo communication.

In his work on group problem solving and human behavior, Maier [16] distinguishes between the quality or adequacy of a solution, and the acceptance and motivation of group members to carry out their decision. The primary concern of this research is the effect of communication mode on the development of a negotiated solution and the implementation of that solution. The convergence process of developing a shared meaning among group members can be linked to the affiliation process of comparing views and negotiating shared understanding. For the convergence process, media that focus the communication onto a single issue help in developing a common shared understanding. One of the underlying premises in the cohesivenessperformance relationship is that increased cohesiveness leads to increased cooperation and that increased cooperation leads to increased performance. While conformity has some potentially undesirable outcomes, there are many compelling positive outcomes associated with conformity. The degree of interaction required by the group to be successful can be viewed as an important determinant of the cohesiveness-performance relationship. This model predicts that both the quality of the strategy and the cohesiveness of the group will have a positive impact on task performance. As such the third hypothesis is:

H3a: Higher quality strategy decisions will result in higher task performance.

H3b: Higher cohesiveness will result in higher task performance.

\section{RESEARCH METHODOLOGY}

The data used in this study was collected as a part of an ongoing research effort into the use and impact of collaborative technologies. For geographically dispersed teams, meeting in a face-toface setting can be difficult, time-consuming and expensive. The experimental design consisted of $2 \mathrm{x}$ 2 factorial design text versus audio, and video versus no video.

This study is designed to test the effect of audio versus text-based communication together with the marginal effect of a video medium on a group's ability to develop a strategy. This design provides alternate communication media currently available to support virtual teams working in a synchronous environment. Each of these media provides a different combination of the communication capabilities represented by concurrency and feedback.

1. Text only communication supports multiple simultaneous conversations (high concurrency) but does not provide immediate feedback.

2. Text communication with video and no audio is high in concurrency and will have an increased level of feedback from the video.

3. Audio only communication does not support multiple simultaneous conversations (low in concurrency) but allows a medium level of feedback.

4. Audio communication with video (Video Conferencing) is low in concurrency but will have an increased level of feedback. 


\section{Resource Dilemma Task}

The resource dilemma task placed each group member in charge of their own fishing boat where they decided how many fish they would catch from the common pool of fish and when they would return to port. The basic paradigm of a renewable resource is similar to that used by Jorgensen and Papciak [12] and Messick and McClelland [17] to examine individual behavior. The task used for this study has virtual teams communicate using one of the four different communication media. The task required each group to develop a strategy for maximizing income based upon limited information. A graphicsbased simulation program developed by Gifford and Wells [9] simulates the harvesting process of fisheries stock by multiple fishers and a renewal of stock through the natural reproduction process. The performance of groups using different media was measured using the quality of the group's strategy decision.

\section{Experimental Sessions}

Data has been collected from 64 teams utilizing White Plain's CU-SeeMe software. Teams consisted of 3 to 4 individuals who had worked together on two prior projects. For purposes of consistency, the virtual meetings were held in a lab setting with separate identically configured "breakout" rooms. All of the rooms contained identically configured computers and were connected using a 100MB Ethernet network. Videum (C) cameras with capture boards and headsets with attached microphones were installed to support audio and video communication channels. Setting for each of the different conditions, text-only, audio-only, text-video and audio-video were randomly assigned and the systems reconfigured prior to each team's scheduled meeting. Each individual participated in a training session to develop proficiency with the specific features of the collaborative technology assigned to their team. The independent variables in this study were concurrency level, text versus audio, and feedback level, the absence or presence of video.

The control variables were the task, the subject pool, and the experimental environment. The fishing task provides the same scenario to the group members regardless of the experimental condition. The experimental procedure and the laboratory setting were tightly controlled to ensure equality among all the groups. Groups comprised of 3-4 members who had worked together on two prior projects and had the expectation of future meetings to complete other projects. Individuals reported a medium to high level of experience in working with groups and making actual decisions and spent an average of 3.9 hours per week in meetings (where a meeting is defined as two or more people working together for a business, school, or other organizational purpose). In addition, individuals reported good typing skills (30 wpm error free) and use of electronic mail and web browsing of greater than 5 times per week.

\section{GENERAL RESULTS}

This research project studies the effect of different communication media on groups involved in a decision making task. The task involves two distinct activities, the development of a group strategy and the implementation of that strategy. The strategy plan and the group cohesiveness data from the strategy development process were used to test the underlying MST dimensions of conveyance (high concurrency and low feedback) and convergence (low concurrency and high feedback). Means for the dependent variables are presented in Table 2.

Table 2: Means for Variables by Treatment

\begin{tabular}{|l|l|r|r|r|r|}
\hline & $\begin{array}{c}\text { Dependent } \\
\text { Variables }\end{array}$ & $\begin{array}{c}\text { Text } \\
\text { Only }\end{array}$ & $\begin{array}{r}\text { Text- } \\
\text { Video }\end{array}$ & $\begin{array}{c}\text { Audio- } \\
\text { Only }\end{array}$ & $\begin{array}{c}\text { Audio- } \\
\text { Video }\end{array}$ \\
\hline $\mathrm{H}(1)$ & Strategy & 1341 & 1302 & 1133 & 1562 \\
& & $(478)$ & $(467)$ & $(396)$ & $(414)$ \\
\hline $\mathrm{H}(2)$ & Cohesiveness & 4.61 & 4.47 & 4.43 & 4.57 \\
& & $(0.40)$ & $(0.44)$ & $(0.523)$ & $(0.568)$ \\
\hline & Task & 1169 & 1243 & 1166 & 1467 \\
& Performance & $(442)$ & $(417)$ & $(434)$ & $(379)$ \\
\hline
\end{tabular}

\section{Results by Research Hypothesis}

The hypotheses were designed to measure three different sets of data presented in the research model: the impact of communication media on strategy decision and cohesiveness; the impact of strategy decision and cohesiveness on task performance; and the impact of task performance on subsequent strategy decisions and cohesiveness. The individual hypotheses tested each relationship of the overall model. Hypotheses 1 and 2 used a series of 6 individual T-tests to compare the difference in strategy and cohesiveness across different pairs of communication media. Pearson correlation coefficients and regression analysis were used to test hypothesis 3 (predicting positive relationships between strategy decisions/cohesiveness and task performance) and hypothesis 4 (predicting positive relationships). The following discussion presents a statistical analysis of the research hypotheses proposed in this study.

Hypotheses 1 and 2 were designed to test the impact of the different communication media. The 
difference in decision strategy and group cohesiveness between text-only and audio-only communication (hypotheses 1a and 2a) are presented in Table 3. The results comparing the addition of video to audio-only communication and to text-only communication (hypothesis $1 \mathrm{~b}$ and $2 \mathrm{~b}$ ) are presented in Tables 4 and 5.

Table 3: Results of $t$-tests Comparison of Text-only to Audio-only Communication

\begin{tabular}{|c|c|c|c|c|c|}
\hline Condition & $\begin{array}{c}\text { Text- } \\
\text { only } \\
(\mathrm{N}=14)\end{array}$ & $\begin{array}{c}\text { Audio- } \\
\text { only } \\
(\mathrm{N}=14)\end{array}$ & $t$ & Pr>t & $\begin{array}{c}\text { Signif- } \\
\text { icance }\end{array}$ \\
\hline $\begin{array}{c}\text { Strategy } \\
\text { H(1a) }\end{array}$ & & & & & \\
\hline Mean & 1341 & 1133 & 2.42 & 0.111 & No \\
\hline Std Dev & $(478.6)$ & $(396.9)$ & & & \\
\hline $\begin{array}{c}\text { Cohesiveness } \\
\text { H(2a) }\end{array}$ & & & & & \\
\hline Mean & 4.61 & 4.43 & 2.19 & 0.117 & No \\
\hline Std Dev & $(0.397)$ & $(0.523)$ & & & \\
\hline
\end{tabular}

Table 4: Results of $t$-tests Comparison of Audio-only to Audio-Video Communication

\begin{tabular}{|c|c|c|c|c|c|}
\hline Condition & $\begin{array}{c}\text { Audio- } \\
\text { only } \\
(\mathrm{N}=14)\end{array}$ & $\begin{array}{c}\text { Audio- } \\
\text { Video } \\
(\mathrm{N}=14)\end{array}$ & $t$ & Pr>t & $\begin{array}{c}\text { Signif- } \\
\text { icance }\end{array}$ \\
\hline $\begin{array}{c}\text { Strategy } \\
\text { H(1b) }\end{array}$ & & & & & \\
\hline Mean & 1133 & 1562 & 61.0 & 0.048 & Yes \\
\hline Std Dev & $(396.9)$ & $(414.1)$ & & & \\
\hline $\begin{array}{c}\text { Cohesiveness } \\
\text { H(2b) }\end{array}$ & & & & & \\
\hline Mean & 4.43 & 4.57 & 0.94 & 0.167 & No \\
\hline Std Dev & $(0.523)$ & $(0.568)$ & & & \\
\hline
\end{tabular}

Table 5: Results of $t$-tests Comparison of Text-only to Text-Video Communication

\begin{tabular}{|c|c|c|c|c|c|}
\hline Condition & $\begin{array}{c}\text { Text- } \\
\text { only } \\
(\mathrm{N}=14)\end{array}$ & $\begin{array}{c}\text { Text- } \\
\text { Video } \\
(\mathrm{N}=14)\end{array}$ & $t$ & Pr>t & $\begin{array}{c}\text { Signif- } \\
\text { icance }\end{array}$ \\
\hline $\begin{array}{c}\text { Strategy } \\
\text { H(1b) }\end{array}$ & & & & & \\
\hline Mean & 1341 & 1302 & 0.003 & 0.415 & No \\
\hline Std Dev & $(478.6)$ & $(467.9)$ & & & \\
\hline $\begin{array}{c}\text { Cohesiveness } \\
\text { H(2b) }\end{array}$ & & & & & \\
\hline Mean & 4.61 & 4.58 & 0.21 & 0.251 & No \\
\hline Std Dev & $(0.397)$ & $(0.440)$ & & & \\
\hline
\end{tabular}

Hypothesis 1a postulated that the higher concurrency of text-only communication would allow groups to develop better strategies. Hypothesis 2a postulated that the low concurrency and high immediacy of feedback of audio-only communication would result in higher cohesiveness. The results in Table 3 indicate that while the text-only groups developed better strategies than the audio-only groups, $\mathrm{H}(1 \mathrm{a})$, the difference is not significant at the .10 level. The difference in cohesiveness between the text-only and audio-only groups, $\mathrm{H} 2$ (a) is opposite of the hypothesized direction and non-significant.

The results in Table 4 and Table 5 support hypothesis $1 \mathrm{~b}$, that the addition of video has a positive impact on the quality of the strategy decision, only for the audio communication ( $t=60.99$, $\operatorname{Pr}=0.048$ ). Although the addition of video to the audio-only produced higher group cohesiveness, 4.57 versus 4.43 , the difference was not statistically significant. Finally the addition of video to the textonly communication produced results which were the opposite of the hypothesized direction for both strategy decision and cohesiveness but nonsignificant. For the first part of the research model, the results support the hypothesized impact of communication media on strategy decision. The second and third parts of the model focus on the relationships between task performance and the variables strategy decision and cohesiveness across all communication media.

Hypothesis 3 examines two relationships, one between the quality of strategy decision and task performance and a second between commitment to the task and task performance. Table 6 represents the impact of the strategy and cohesiveness on task performance (hypotheses 3a and 3b). The results support the higher $\mathrm{H}(3 \mathrm{a})$, that higher quality strategy decisions result in higher task performance $\left(\mathrm{R}^{2}\right.$ $=0.519, \quad p=0.0001)$ for all the different communication media. The results do not support $\mathrm{H}(3 \mathrm{~b})$, that higher cohesiveness results in higher task performance.

Table 6: Impact of Strategy Decision and Cohesiveness on Task Performance

\begin{tabular}{|c|c|c|c|c|c|}
\hline $\begin{array}{c}\text { Dependent } \\
\text { Variable }\end{array}$ & $\begin{array}{c}\text { Regression } \\
\text { Coefficient }\end{array}$ & $\mathrm{R}^{2}$ & $\mathrm{~N}$ & $\mathrm{p}$ \\
\hline $\begin{array}{c}\mathrm{H}(3 \mathrm{a}) \text { Task } \\
\text { Performance }\end{array}$ & Strategy & 0.720 & 0.519 & 56 & 0.0001 \\
\hline & & & & & \\
\hline $\begin{array}{c}\mathrm{H}(3 \mathrm{~b}) \text { Task } \\
\text { Performance }\end{array}$ & $\begin{array}{c}\text { Cohesive- } \\
\text { ness }\end{array}$ & 0.045 & 0.002 & 56 & 0.7430 \\
\hline
\end{tabular}

\section{Limitations}

In reviewing the design of work teams, Kock [14] discusses the impact of variations in cognitive effort on the variations in use of collaborative technologies.. There are clearly many factors which impact the effectiveness of work-group that are outside the scope of this study. The limitations of this research need to be kept in mind when interpreting 
the results. First, the research findings are based on data collected in an experimental setting. While subjects have significant experience with text-only and audio-only communication, they have little experience with video-conferencing. Second, the use of small groups working for a brief period could be another limitation. Since many tasks in organizations involve larger groups working over extended periods, the external validity of this study could be reduced. Third, the resource dilemma is basically a chooseand-execute task. Although the task does require some negotiation of personal versus overall group interest, the negotiation process is not the focus of the task for novice subjects. Finally, the satisfaction of teams utilizing the different technologies has not been evaluated. The perceptions of satisfaction of and usability are important to the continued use of many types of technologies.

\section{CONCLUSIONS}

Building on prior work in communication media, the results suggest that for tasks which require the development of a common understanding and an agreed upon solution among team members, the capabilities of video-conferencing are better matched to communication requirements of virtual teams than audio-only communication. The communication process allows individuals in virtual teams to process information, test ideas, exchange opinions, and reach a consensus. As problem solving and decisionmaking teams move from face-to-face to virtual environments it is important to re-examine how the use of collaborative technologies is affected by this lack of physical interaction. The results of previous studies clearly show that the lower media richness and lower satisfaction of different collaborative technologies, when compared to face-to-face meetings, do not result in lower quality of decisions. This model postulates the impact of different collaborative technologies for virtual teams.

The use of multimedia technologies and Internetbased systems can enhance communication and the resulting decisions for virtual teams. If an organization has teams which cannot meet in a faceto-face setting, the addition of video to existing audio-based communication can improve their ability to make decisions. The finding extends the current knowledge for the interaction of video with text and audio-based communication media for dispersed groups. By focusing only media that support geographically dispersed teams, the research model uses the concurrency and feedback features of media synchronicity to analyze the impact of communication media on virtual teams. These factors will help to provide a more complete understanding of how the media characteristics of concurrency and feedback impact the underlying communication processes of conveyance and convergence for virtual teams.

\section{REFERENCES}

1. Campbell, J. "Videoconferencing: A case for strategic distributed group support," Singapore Management Review, 17:2, 1995, pp. 35-48.

2. Carmel, E. and R. Agarwal. "Tactical approaches for alleviating distance in global software development," IEEE Software, 18:2, 2001, pp. 22-29

3. Cartwright, D., \& A. Zander. Group Dynamics: Research and Theory. New York: Harper \& Row, 1968.

4. Dennis, A.R., J.S Valacich, C. Speier, and M.G. Morris. "Beyond media richness: An empirical test of media synchronicity theory," Proceedings of 1998 Annual Hawaii International Conference on Systems Science, Maui, January 1998, pp. 4857.

5. DeSanctis, G., and R.B. Gallupe. "A foundation for the study of group decision support systems," Management Science, 33:5, 1987, pp. 589-609.

6. Festinger, L. "Informal social communication," Psychological Review, 57:5, 1950, pp. 271-282.

7. Fisher, B. A. Small Group Decision Making: Communication and the Group Process. New York: McGraw-Hill Book Company, 1974.

8. Gallupe, R.B. and G. DeSanctis. "Computerbased support for group problem-finding: An experimental investigation," MIS Quarterly, 12:2, 1988, pp. 277-296.

9. Gifford, R. and J. Wells. "FISH; A commons dilemma simulation," Behavioral Research Methods, Instruments, \& Computers, pp. 437441, 1991.

10. Hiltz, S.R., K. Johnson,, and M. Turoff. "Experiments in group decision making: Communication process and outcome in face-toface versus computerized conferences," Human Communication Research, 13:2, 1986, pp. 225252.

11. Janvenpaa, S. and B. Ives. "The global network organization of the future: information management opportunities and challenges," Journal of Management Information Systems, 10:4, 1994, pp. 25-58.

12. Jorgeson, D.O. and A.S. Papciak. "The effects of communication, resource feedback, and identifiability on behavior in a simulated commons," Journal of Experimental Social Psychology, 17:4, 1981, pp. 373-385. 
13. Kerr, N.L. and C.M. Kaufman-Gilliland. "Communication, commitment, and cooperation in social dilemmas," Journal of Personality and Social Psychology, 66:3, 1994, pp. 513-529.

14. Kock, M. “The psychological model: Towards a new theory of computer-mediated communication based on darwinian evolution." Organization Science. 15:3, 2004, pp. 327-348.

15. Lea, M. and R. Spears. "Computer mediated communication, de-individualization and group decision making", in S. Greensberg (Ed.), Computer-Supported Cooperative Work and Groupware, London: Academic Press, 1991, pp. 153-173.

16. Maier, N.R.F. Principles of Human Relations, New York: John Wiley, Academic Press.

17. Messick, D.M. and C.L. McClelland. "Social traps and temporal traps," Personality and Social Psychology Bulletin, 9:1, 1983, pp. 105-110.

18. Meyerson, D., K.E. Weick, and R.M. Kramer. "Swift trust and temporal groups," in Kramer, R.M. and T.R Tyler (Eds.), Trust in Organizations: Frontiers of Theory and Research, Thousand Oaks, Ca: Saqge Publications, 1996, pp. 166-195.

19. Mills, T.M. The Sociology of Small Groups, Englewood Cliffs, NJ: Prentice-Hall, 1967.

20. Pasternack, B. and A.Viscio. The Centerless Corporation, New York: Simon and Schuster, 1998.

21. Potter, R. E., P.A. Balthazard, and R.A. Cooke.. Virtual team interaction: assessment, consequences, and management. T. Team Performance Management: An International Journal, 6:7/8, 2000, pp. 131-137.???

22. Short, J. E., E. Williams, and B. Christie. The Social Psychology of Communications. London: John Wiley, 1976.

23. Suh, K.S. "Impact of communication medium on task performance and satisfaction: An examination of media-richness theory”, Information and Management, 35:5, 1999, pp. 295-312.

24. Trevino, L.K., Webster, J. and Stein, W.W. "Making connections: Complementary influences on communication media choices, attitudes, and use,” Organization Science, 11:2, 2000, pp. 163-182.

25. Weick, K.E., and D.K. Meader. "Sensemaking and group support systems," In J. S. Valacich (Ed.), Group Support Systems: New Perspectives,. New York: Macmillian Publishing, 1993, pp. 230-252

26. Zigurs, I. and S. Qureshi. "Managing the extended enterprise, creating value from virtual spaces," in Dickerson, G. and G. DeSanctis (Eds.), Information Technology and the Future Enterprise: New Models for Managers. New York: Prentice-Hall, 2001. 